\title{
Forces de Verlaine. Textes réunis par Yann Frémy
}

\section{Nicola Ferrari}

\section{(Q) OpenEdition}

\section{Journals}

\section{Edizione digitale}

URL: http://journals.openedition.org/studifrancesi/9318

DOI: 10.4000/studifrancesi.9318

ISSN: 2427-5856

\section{Editore}

Rosenberg \& Sellier

\section{Edizione cartacea}

Data di pubblicazione: 1 juin 2008

Paginazione: 218

ISSN: 0039-2944

\section{Notizia bibliografica digitale}

Nicola Ferrari, «Forces de Verlaine. Textes réunis par Yann Frémy», Studi Francesi [Online], 154 (LII | I) |

2008, online dal 30 novembre 2015, consultato il 11 janvier 2021. URL: http://

journals.openedition.org/studifrancesi/9318; DOI: https://doi.org/10.4000/studifrancesi.9318

\section{Questo documento è stato generato automaticamente il 11 janvier 2021.}

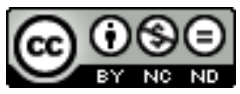

Studi Francesi è distribuita con Licenza Creative Commons Attribuzione - Non commerciale - Non opere derivate 4.0 Internazionale. 


\title{
Forces de Verlaine. Textes réunis par Yann Frémy
}

\author{
Nicola Ferrari
}

\section{NOTIZIA}

Forces de Verlaine. Textes réunis par Yann FRÉMY, «Revue des Sciences Humaines», n. 285, 2006, pp. 229.

Intendere l'esperienza artistica di Verlaine, oggi, significa riconoscerne pienamente la centralità, rispetto alle consolidate posizioni di Baudelaire, Rimbaud e Mallarmé, riscoprirne lo slancio energetico senza negarle la profonda sensibilità, ripensarne l'opera nella sua totalità dissolvendo i pregiudizi critici sulla discontinuità qualitativa della produzione poetica e l'insipienza della scrittura in prosa. Questo ambizioso e partecipato intento programmatico ha mosso Yann FRÉMY a coordinare un'agguerrita cordata di studiosi - animati dall'identica istanza riabilitativa - per misurare, con gli strumenti attuali, le forze di un Verlaine poeta profondamente cosciente della sua creazione, la cui opera non è più riducibile alle sole Romances sans paroles: se Solenn DUPAS dimostra la natura eteronima, artificiale dell'io poetico verlainiano, rivendicando la natura finzionale, mediata, di quelle connotazioni di semplicità e immediatezza espressiva assunte come stereotipo critico, nel suo contributo, il curatore argomenta l'importanza della Bonne Chanson, leggendone acutamente il settimo componimento, nella definizione inaugurale di quella sintesi disgiuntiva di grazia e violenza, scienza, eleganza e vigore, che Richard avrebbe attribuito al solo Rimbaud. Il riconoscimento della complessità dell'opera di Verlaine implica la necessità di una pluralità di approcci critici, rappresentata dalle differenti sezioni della monografia: dalle ricerche documentaristiche (Steve MURPHY presenta due prologhi manoscritti, Michael PAKENHAM, sulla base di documenti trascurati, corregge con sarcastico risentimento le edizioni critiche approntate da Jacques Borel delle CEuvres en prose complètes di Verlaine) alla comparazione interartistica, che investiga quanto la sperimentazione poetica traduca e 
si traduca nei codici pittorici e musicali: Arnaud BERNADET affronta, nello spazio del dialogo tra Verlaine e la pittura di Rembrandt, nella tensione di sguardo e scrittura, la possibilità di dire poeticamente l'ammirazione estetica, di rendere altrimenti visibile nella creazione letteraria la creazione iconica; David A. POWELL isola dal mare sconfinato di intonazioni dell'opera di Verlaine - provocatoriamente musicale fin dai titoli - le interpretazioni di Clair de lune elaborate da Debussy e Fauré, confrontandone la letteralizzazione sonora dei 'tropi musicali', gli usi figurati della musica nel testo (ma, a dispetto di una fenomenologia analitica dettagliata, le conclusioni non sembrano sfuggire a una certa genericità). Collocata in questa sezione, l'acuta interpretazione dell'ambientazione e della messa in scena dei ritratti fotografici di Verlaine compiuti da Domac come ricostruzione iconica di un'identità artistica fittizia, confronto tra (rappresentazione della) esistenza e (elaborazione della) leggenda, la relazione di Jacqueline GUITTARD offre un significativo contributo all'indagine biografica. Pierre BRUNEL, nel tentativo di smontare il consolidato luogo critico che, per rafforzare il mito di Rimbaud, lega le fasi genuinamente creative della vita di Verlaine alle apparizioni del genio adolescente, chiarifica, nella documentata e precisamente datata ricostruzione della vicenda elaborativa di Cellulairement, le effettive direzioni di influenza, i legami di reciproca attrazione, il campo di forze poetiche messo in gioco dalla relazione paritetica tra i due creatori nella loro Saison en enfer. Se l'estrema tensione nella volontà di fare emergere la figura di un nuovo Verlaine, accumuna tutti gli studi, è nella sezione intitolata alla Metrica Retorica Stilistica di Verlaine, che l'istanza critica si argomenta nella maniera più convincente. La riflessione di Jean-Louis AROUI sul corpus di triolets ma soprattutto l'analisi delle innovazioni metriche che Steve MURPHY ha indagato dentro l'apparente immediatezza espressiva di À une femme e lo studio generale di Jean-Pierre вовіLцот sulle cesure dell'alessandrino e le strutture di ripetizione e variazione di sequenze fraseologiche in un serrato riconoscimento di eredità e figliazioni da Baudelaire a Dino Campana, dimostrano significativamente quanto la vera vita di Verlaine, la sua stessa pretesa di comunicazione diretta (eredità dell'ideologia romantica), siano effetto di una moderna presa di distanza, prodotto retorico della più consapevole costruzione letteraria. 